\title{
REVIEW
}

\section{Bench-to-bedside review: Vaccine protection strategies during pandemic flu outbreaks}

Joel V Chua' and Wilbur H Chen*2

\begin{abstract}
Vaccination is the most effective means for the prevention of influenza, including pandemic strains. An ideal pandemic influenza vaccine should provide effective protection with the fewest number of doses in the shortest amount of time, and among the greatest proportion of the population. The current manufacturing processes required for embryonated chicken-egg-based influenza vaccines are limited in their ability to respond to pandemic situations - these limitations include problems with surge capacity, the need for egg-adapted strains, the possibility of contamination, and the presence of trace egg protein. Several vaccine strategies to circumvent the deficiencies intrinsic to an egg-based influenza vaccine are in various phases of development. These include the use of cell-culture-based growth systems, concomitant use of adjuvants, whole virus vaccines, recombinant protein vaccines, plasmid DNA vaccines, virus-like particle vaccines, and universal flu vaccines.
\end{abstract}

\section{The ever-present threat of influenza}

Vaccines are the most effective mitigation strategy to protect against disease caused by influenza. The average seasonal influenza epidemic is estimated to cause 36,000 deaths in the United States annually [1], and much more worldwide. The morbidity and mortality during a pandemic is expected to be far greater, however, as seen in the 1918 Spanish flu wherein between 40 and 50 million people died $[2,3]$.

The current novel $2009 \mathrm{H} 1 \mathrm{~N} 1$ virus arose and circulated rapidly such that a global pandemic was declared within 2 months of initial recognition. Thankfully, this

*Correspondence: wchen@medicine.umaryland.edu

${ }^{2}$ Center for Vaccine Development, 685 W Baltimore Street, HSF1, Room 480, Baltimore, MD 21201, USA

Full list of author information is available at the end of the article virus has generally been associated with mild illness; however, it is responsible for excessive hospitalizations and deaths among the young, pregnant women, and those with underlying medical conditions. The virus caused significant disease during the Southern Hemisphere's winter and caused, as expected, an early influenza wave in the Northern Hemisphere, but it was not associated with more severe disease, as in the secondwave phenomenon observed during the early winter of the 1918 pandemic. Accordingly, there is an urgent need to rapidly develop and distribute vaccines capable of eliciting protective immunity for the most susceptible segments of the population.

\section{Current seasonal and pandemic influenza vaccines}

Influenza vaccines have been in existence since the mid1940s [4]. Since then there have been advancements in manufacture and purification techniques, leading to modern vaccines with improved safety profiles and standardized potency. Broadly, there are two types of seasonal influenza vaccines currently licensed for use: parenteral trivalent inactivated vaccine (TIV), and mucosal (nasal) live attenuated influenza vaccine (LAIV). In the United States, nonadjuvanted TIV and LAIV are approved for use. In Europe, LAIV and both adjuvanted and nonadjuvanted TIV are approved for use. A separate LAIV vaccine is also licensed for use in Russia.

Twice each year, the World Health Organization uses data from the Global Influenza Surveillance Network to select three candidate viruses for the updated seasonal vaccine. The selected strains are the ones predicted to circulate during the subsequent season of each hemisphere's winter. The Northern Hemisphere strain selection is performed in February, the Southern Hemisphere selection in September. In recent years, the vaccine contains two influenza A viruses, H1N1 and H3N2 subtypes, and an influenza B virus. Once candidate strains are identified, seed viruses are further adapted for highyield growth in chicken eggs through genetic reassortment techniques to produce the vaccine virus strain.

After optimization of growth conditions, manufacturers create bulk quantities of vaccine virus from inoculated embryonated chicken eggs. The vaccine is 
purified by a standardized process of zonal centrifugation or column chromatography from virus-containing egg allantoic fluid, and during this process the virus is inactivated by formaldehyde. Treatment with detergents disrupts the viral envelope and leads to split virion or subvirion vaccines. Prior to vaccine distribution, each batch or lot of vaccine is tested for sterility and potency, using highly standardized reference reagents to ensure the correct concentration of vaccine antigen. In reference to H1N1 pandemic vaccines, these biologic reagents may only be obtained from Australia's Therapeutic Goods Administration, Japan's National Institute of Infectious Disease, the UK's National Institute for Biological Standards and Control, or the US Food and Drug Administration (FDA) [5].

A LAIV was first licensed for human use in the United States in 2003. It is approved for use in healthy and immunocompetent individuals, aged 2 to 49 years. When administered intranasally, LAIV provides superior protection in children [6,7] compared with TIV, and results in herd immunity in children and adults [8]. The US LAIV backbone (or the master donor virus) was generated by serial passage of an influenza $\mathrm{A}$ strain (A/ Ann Arbor/6/60 H2N2) and an influenza B strain (B/Ann Arbor/1/66) at lower temperatures in primary chick kidney cells, resulting in viruses that are temperature sensitive, cold adapted, and attenuated $[9,10]$. Each of the three LAIV strains is prepared using reverse genetic reassortment. Plasmids containing six master donor virus genes and two wild-type virus genes, representing hemagglutinin (HA) and neuraminidase (NA), are electroporated into Vero cells to produce the vaccine seed strains [6]. On the other hand, a Russian LAIV has been in use since the mid-1970s wherein the master donor virus is based on a serial passage-derived, cold-adapted A/ Leningrad/134/57 H2N2 virus and the B/USSR/60/69 virus $[11,12]$. The Russian vaccine reassortant is produced by co-culturing the master donor virus with wild-type virus, and no reverse genetics is used.

Once generated, the bulk viruses for the vaccine are mass produced using embryonated chicken eggs. The viruses are filtered and concentrated, but not inactivated nor disrupted, such that the final vaccine contains live attenuated viruses expressing the contemporary HA and NA of that season.

\section{Current basis of influenza vaccine protection}

The surface of the enveloped influenza virus is decorated by two main antigenic determinants, HA and NA, which play important roles in virulence and pandemic potential. As such, they are the primary antigenic target of influenza vaccines.

Strain-specific serum anti-HA antibodies prevent binding of the virus to host target receptors, and result in efficient viral neutralization [13]. Vaccination that induces sufficiently high amounts of anti-HA antibodies are necessary to protect an individual from influenza infection. A serum hemagglutination-inhibition assay is technically simple to perform, automatable, and represents the conventional means for assessing immunogenicity; a hemagglutination-inhibition titer $\geq 1: 40$ has traditionally defined seroprotection and has been associated with a $>50 \%$ reduction in risk of influenza infection [14]. A viral neutralization assay, however, is a functional assay that is technically more difficult to perform and requires live viruses, and therefore may require a biosafety level 3 facility. The hemagglutinationinhibition assay typically correlates well with the viral neutralization assay.

Anti-NA antibodies may contribute to protective immunity by blocking the viral NA from releasing replicating viruses and allowing the subsequent dissemination of the virus to other susceptible host cells. Although anti-NA antibodies can mitigate the severity of influenza infection [15-18], they alone do not neutralize the virus nor prevent infection [19].

Both inactivated parenteral and nasally delivered LAIV may induce anti-HA antibody, but LAIV may provide protection against influenza despite the absence of a serum anti-HA antibody response [6]. Since LAIV is mucosally delivered, secretory IgA may be elicited. Complexes formed by dimeric secretory IgA are potentially more efficient in inhibiting viral entry than IgG or monomeric IgA [20]. High levels of anti-HA secretory IgA antibodies can be detected in nasal washes within 2 weeks and may persist for 1 year [21]. No standard antibody assay, however, has been established for evaluating LAIV efficacy. Licensure of the current LAIV was on the basis of significant efficacy in multiple studies and not immunogenicity.

Cell-mediated immunity probably plays an important role in the control and prevention of influenza infection, but the identification of cell-mediated immunity correlates of protection has been elusive. The elicitation of humoral immunity requires a complex and carefully orchestrated interplay of the cellular immune system, and no single marker has sufficiently predicted vaccine response.

\section{Goals of pandemic influenza vaccines}

A major antigenic shift resulting in a pandemic potential influenza virus is anticipated to cause a major threat to public health. This phenotypic change is predicted to result in higher morbidity and mortality - especially among segments of the population that are historically at lower risk for severe disease due to seasonal influenza, such as healthy young adults. In addition, pandemics have been typified by higher transmissibility and 
successive waves [22]. Modern international travel, widespread migration, and fluid borders all facilitate the more rapid spread of pandemic influenza viruses.

For these reasons, a pandemic vaccine should ideally possess certain characteristics. The vaccine should provide protection with the fewest number of doses (that is, a single dose) in the shortest amount of time, and among the greatest proportion of the population (for example, infants, elderly and immunocompromised people). In order to ensure that the population will accept vaccination, the vaccine must have a high degree of safety and little reactogenicity. Other considerations include vaccines that are temperature stable (do not require coldchain storage) and that avoid the need for needle and syringe delivery. In addition, rapid development and production of massive quantities of vaccine should maintain a consistent and reliable manufacturing process.

These vaccines must be evaluated prior to approval for use under extraordinarily compressed timelines. The challenge for the US FDA and other national regulatory authorities is to ensure safe and effective vaccines in a timely fashion through the evaluation of clinical data to support licensure [23]. The US FDA can facilitate rapid approval of pandemic vaccines based on limited clinical studies on safety and immunogenicity if the manufacturer has a US-licensed seasonal influenza vaccine and is using the same manufacture process. Under this instance, the vaccine is considered a strain change. On the other hand, if the manufacture process has not gained previous US licensure, safety and effectiveness studies are required. The US FDA guidance for accelerated approval of pandemic vaccines, however, potentially permits the use of an 'acceptable surrogate marker of activity that is reasonably likely to predict clinical benefit' [24]. Alternatively, the US FDA has the authority to grant Emergency Use Authorization of an unapproved product, provided some critical criteria are met, during a national public health emergency; this status ends when the emergency declaration is terminated. As an example, the agency recently issued Emergency Use Authorizations for the use of oseltamivir in patients $<1$ year old and for intravenous peramivir. Consequently, US pandemic vaccines are pragmatically constrained to licensed manufacture processes.

In the European Union, the European Medicines Agency has a slightly different regulatory process, allowing a rolling review procedure for the submission of data as they become available, in comparison with the single formal application procedure of the US FDA. In Europe, some manufacturers have adopted the development of a core dossier or mock-up vaccine strategy. This approach includes the collection of preclinical, safety, and immunogenicity data on an index influenza virus that has not recently circulated among humans and thereby may mimic the novelty of a pandemic virus [25]. Using this strategy, novel 2009 H1N1 adjuvanted influenza vaccines and cell-culture-based vaccines were approved for use in the European Union.

\section{Current influenza vaccines and inherent limitations}

The current manufacture of most influenza vaccines is dependent on generating large virus stocks from eggs. The requisite supply of suitable eggs is subject to erratic production by stressed or ill chicken flocks, contamination, and other unpredictable events. Eggs need to be specific pathogen free, quarantined, and constantly monitored to make certain they remain disease free before entering the supply chain.

A vaccine virus should be optimally adapted to grow in eggs to ensure sufficient virus yield. Typically, one egg leads to one dose of inactivated seasonal flu vaccine. There have been reports of growth yields as low as 20 to $50 \%$ with the novel $\mathrm{H} 1 \mathrm{~N} 1$ vaccines, compared with seasonal viruses (Center for Disease Control and Prevention, unpublished data). Wild-type avian $\mathrm{H} 5 \mathrm{~N} 1$ viruses were problematic because replication leads to killing of the chicken embryo. The global production capacity of influenza vaccine is estimated to be 300 million to 350 million doses annually or approximately 900 million doses of monovalent pandemic vaccine (assuming a single $15 \mu \mathrm{g}$ dose) [26]. Only one-sixth of the world's population may therefore have the opportunity to be immunized.

The time required to prepare the vaccine from virus stocks to the point of filling and distribution of vials is a further limitation. Under normal circumstances, there is an 8-week to 12-week period following receipt of wildtype virus to the release of a safe reference vaccine virus to the manufacturers. The manufacturer may require a few weeks to generate high-growth reassortant viruses. Another 8-week to 12 -week period may be required to produce the virus stocks, to concentrate and purify the antigen, and to fill vaccine. Lastly, each vaccine lot must be quality tested prior to release.

Reverse genetic techniques, using plasmid rescue, have enabled researchers and manufacturers to produce highyield viruses that express the relevant surface antigens, but remain nonpathogenic or attenuated. These techniques have also been found to be suitable for largescale vaccine manufacturing [27].

The two major bacterial contaminants of concern are Salmonella and Campylobacter, both of which can colonize chickens and contaminate eggs. During the 1976 Swine Flu vaccine campaign there was an increased incidence of Guillain-Barré syndrome (GBS) [28], an ascending motor paralysis characterized by autoimmune demyelination. Although a link between an antecedent Campylobacter jejuni infection and GBS is known, this has not been established as the cause of GBS with the 
1976 influenza vaccine [29]. The association of GBS and influenza vaccine has not been observed with subsequent influenza vaccines. A biologic mechanism for postimmunization GBS has been hypothesized to involve the synergistic effects of endotoxins (the product of Salmonella contamination) and vaccine-induced autoimmunity [30]. The presence of autoreactive antibodies against common cellular moieties of neurons (that is, gangliosides), however, has been reported to be associated with GBS [31]. An alternate etiology implicates sialylated HA complexes in the 1976 vaccine that may have provided the molecular mimicry leading to the development of anti-GM1 ganglioside antibodies, thereby leading to excess GBS cases [32]. The analysis of sialylation of $\mathrm{HA}$ in vaccines and the measurement of anti-GM1 antibody have therefore been proposed as a prelicensure requirement [33]. With the current H1N1 pandemic vaccines, there have not been reports of excess cases of GBS beyond the expected baseline rate.

A final limitation of the current influenza vaccine is egg allergy. The manufacture process may cause trace amounts of egg protein to remain in the final vaccine. For those people with serious egg allergy, vaccination is a contraindication. This further illustrates the need to have a pandemic flu vaccine prepared via a different substrate.

\section{Vaccine technologies in development}

Several vaccine strategies to address the critical needs of a pandemic vaccine are in various phases of development. These include the use of cell-culture-based growth systems, concomitant use of adjuvants, whole virus vaccines, recombinant protein vaccines, plasmid DNA vaccines, use of virus-like particles, and universal flu vaccines.

Cell-culture-based growth systems have been approved for use in some European countries. These technologies use African Green monkey kidney (Vero), Madin-Darby canine kidney and other mammalian cell lines as the substrate for viral replication, rather than hen's eggs. Madin-Darby canine kidney cells have been routinely used for viral plaque assays and for clinical isolation of influenza viruses [34-36]. The virus yield using cell culture is comparable with that of eggs [34]. Cell culture offers a reliable and flexible production process, which can be performed using closed aseptic techniques. The process allows for growth of a broad range of authentic virus strains without the need for egg adaptation [37]. Several cell-culture-based influenza vaccines have been shown to be safe, well tolerated and immunogenic in children, healthy young adults, and even among the older population [37-40]. One limitation for rapid licensure of cell-culture-based vaccine is the perceived risk that mammalian cell lines have the potential for tumorigenicity and oncogenicity. The requirement for the presence of animal serum (or fetal bovine serum) in the cell culture medium also presents a special problem for US licensure. Animal serum must be ensured to be free of potential contamination with fungi, bacteria, viruses and agents of transmissible spongiform encephalopathies, and the serum must be readily available and undergo batch variation testing. The use of synthetic proteinbased media, rather than animal serum, may help minimize the risk of transmissible spongiform encephalopathies and viruses, but these techniques are complicated and currently the cost is prohibitive [34,41].

Adjuvants have the potential to boost the immunogenicity of influenza vaccines and thereby are a dosesparing strategy. The only adjuvant that is currently US FDA approved is based on mineral salts (for example, aluminum hydroxide or alum). The interest in more immunostimulatory adjuvants gained momentum when an inactivated avian $\mathrm{H} 5 \mathrm{~N} 1$ vaccine was found to be poorly immunogenic [42] and the addition of alum provided little to no benefit $[43,44]$. Oil-in-water emulsion adjuvant systems have been approved for use with inactivated influenza vaccines in Europe since 1997 (that is, MF-59). In 2009, however, the European Medicines Agency granted approval for ASO3 to be used with formulations of the H1N1 pandemic vaccine. According to the World Health Organization, among the 150 million doses of $\mathrm{H} 1 \mathrm{~N} 1$ pandemic vaccine distributed globally, 30\% are adjuvanted formulations containing either MF-59 or ASO3; primarily in use in Europe and Canada [45]. These adjuvants are safe, associated with mild and transient local reactogenicity, and are otherwise well tolerated [43,44,46-48]. When combined with an inactivated avian $\mathrm{H} 5 \mathrm{~N} 1$ vaccine, MF-59 [46,47] and ASO3 [48] demonstrated superior immunogenicity compared with the unadjuvanted vaccine. Other immunostimulatory adjuvants that might prove safe and effective include saponins, immunostimulatory complexes, and innate immune receptor ligand/agonists (for example, monophosphoryl A, unmethylated $\mathrm{CpG}$, mutant heatlabile enterotoxin, and flagellin). These adjuvants therefore hold the potential to stretch out existing limited vaccine supplies. Furthermore, adjuvants may induce more broadly protective immune responses; the elicited antibodies were cross-reactive against heterologous H5N1 strains $[46,48]$. These heterotypic immune responses may be vital for protection against emerging clades and subclades of pandemic viruses [10].

Whole virus vaccines were originally abandoned because of the increased reactogenicity compared with subvirion vaccines [49]. The 1976 swine flu vaccine was a whole virus vaccine, adding to the stigma of using whole virus vaccines. Inactivated whole virus vaccines, however, can elicit greater immunogenic responses than subvirion vaccines and generate cross-reactive antibodies against 
heterologous influenza strains [50-52]. Currently, a Hungarian-approved and a European Medicines Agencyapproved $\mathrm{H} 1 \mathrm{~N} 1$ whole virus vaccine are available.

Recombinant protein expression systems hold the promise of rapidly generating purified subunit vaccines. One such vaccine is composed of recombinant HA from a Baculovirus expression system. Recombinant HA vaccines are highly purified and contain no antibiotics or egg protein. Because of the higher concentration of antigens, they elicit stronger immune responses with less reactogenicity among healthy young and older adults [5355]. A phase III trial of a recombinant HA vaccine was effective against culture-proven influenza - presenting $86 \%$ cumulative incidence reduction [55]. Nevertheless, the regulatory barrier that exists includes the concern for residual amounts of insect cell and Baculovirus proteins.

Recombinant influenza virus-like particles are another vaccine technology under clinical development. These vaccines mimic the live virus but are unable to replicate, as they lack the internal machinery or genetic material necessary for replication. These virus-like particles are assembled in insect or mammalian cells and simultaneously express HA and NA along with the matrix M1 protein [56]. Virus-like particles are strongly immunogenic and have been found to be protective in seasonal and highly pathogenic influenza virus murine challenge models [57].

Plasmid DNA-based vaccines are yet another promising vaccine technology still at early stages of development. This technology is based on plasmid DNA taken up by muscle cells (transfection) resulting in the expression of plasmid encoded protein [58]. Through direct interaction with $\mathrm{B}$ cells and antigen-presenting cells, the host immune system is stimulated as a result of this transfection [58]. An H5N1 plasmid DNA vaccine that encoded HA, nucleoprotein, and matrix protein M2 provided protection in mouse and ferret models of lethal infection [59]. The potential advantages of this technology include a shorter time for vaccine production, a nondependence on cell culture media, and theoretically eliciting both humoral and cell-mediated immune responses $[58,59]$. These possible benefits have yet to be proven in human trials.

One of the ultimate goals of influenza vaccine research is to develop a universal vaccine that would provide durable and longlasting protection against all influenza A strains, rendering the need for annual vaccination obsolete [60]. One target is the ectodomain of matrix protein 2 (M2e), a highly conserved 23-amino-acid protein component of the virus envelope. Although M2e is a weak immunogen, after combining M2e with a carrier protein (such as hepatitis B virus core particles) the resulting anti-M2e antibody conferred protection in a mouse model of lethal influenza infection [61]. Other highly conserved influenza virus epitopes are under consideration as potential universal flu vaccine candidates.

\section{Pandemic vaccination of the population}

As pandemic vaccines will probably be in short supply, it is paramount that a tiered system of apportionment is developed to identify people at increased risk of substantial morbidity and mortality. In conjunction with allocation, an aggressive campaign to implement the immunization of these at-risk groups will need to be prioritized. Who are the most susceptible? During seasonal epidemics, the predominance of severe disease affects the extremes of age - older people and young infants. With the current $2009 \mathrm{H} 1 \mathrm{~N} 1$ pandemic, the majority of cases have occurred among the younger adult population (age <65), with only $5 \%$ of older people affected [62-64]. Nevertheless, the severity appears to be similar to seasonal epidemics, as one-quarter of the hospitalized patients had at least one underlying medical condition; these conditions include asthma, emphysema, diabetes, chronic cardiovascular disorders, chronic renal disease, neurologic disorders, and immunosuppression of varying etiology $[63,65]$. Pregnant women are at increased risk of complications [65]. As such, the young and pregnant women are among the highest priority for the current H1N1 immunization campaign. For US public policy, the guiding principles concerning vaccination are based on the recognition of groups at high risk of exposure, such as healthcare personnel, close contact with infants $<6$ months of age, and other related caregivers. The World Health Organization recognizes the variability in country-specific $\mathrm{H} 1 \mathrm{~N} 1$ epidemiology and access to vaccine and other influenza-related resources, but also recommends that healthcare workers be among the highest priority to protect the integrity of essential health infrastructure; country-specific conditions should dictate the prioritization of the other highrisk segments of the population to reduce transmission, morbidity, and mortality.

Prior to the initiation of massive immunization, another critical question must be answered. The optimal dose needs to be identified, and this may depend on age and underlying medical conditions. The standard dose of the annual TIV contains $15 \mu \mathrm{g}$ HA per virus strain. With the inactivated subvirion $\mathrm{H} 5 \mathrm{~N} 1$ vaccine, however, a $15 \mu \mathrm{g}$ dose was insufficient [66] and two $90 \mu$ g doses separated by 28 days was necessary to achieve immunogenic responses among $>50 \%$ of recipients $[42,67]$. Therefore, when an influenza virus strain is completely novel - as in the $\mathrm{H} 5 \mathrm{~N} 1$ virus - multiple doses (that is, two or more doses) of vaccine may be necessary to achieve protection. Fortunately, the data show that a single $15 \mu \mathrm{g}$ dose of the $2009 \mathrm{H} 1 \mathrm{~N} 1$ vaccine is sufficient to elicit seroprotection among $>93 \%$ of the healthy young adults $[68,69]$. 
This article is part of a review series on Influenza, edited by Steven Opal. Other articles in the series can be found online at http:// ccforum.com/series/influenza

With regard to the current novel H1N1 pandemic, a handful of pandemic vaccines are being made available in record speed. In the United States, the rapid manufacture of the 2009 H1N1 monovalent vaccines required the open collaboration of the Department of Health and Human Services, academia, and industry at a level of intensity never before experienced. At the global level, the World Health Organization has relied heavily on close collaboration with industry partners and independent experts, such as the Strategic Advisory Group of Experts on Immunization, for the concerted response to the current influenza pandemic. At the time of writing, donated H1N1 vaccine is planned for distribution to 95 resource-poor countries. In the United States, approved vaccines are based on traditional manufacturing processes, although adjuvanted vaccines are under field testing. In Europe and Canada, adjuvanted and cellculture-based vaccines are being used. Vaccination policies guiding these events have been informed by the existing limited data, and continuous epidemiologic surveillance is required to determine the efficacy of the current vaccination campaign and to detect the presence of mutations.

In conclusion, pandemic influenza represents an unpredictable and critical public health emergency. Vaccination remains the most effective means to prevent and control influenza infection. The current manufacturing process, based on chicken eggs, has inherent limitations. Next-generation influenza vaccines and other technologies are under development and provide the promise of improved protection.

\section{Abbreviations}

FDA, Food and Drug Administration; GBS, Guillain-Barré syndrome; HA, hemagglutinin; LAIV, live attenuated influenza vaccine; M2e, matrix protein 2 (an ion channel); NA, neuraminidase; TIV, trivalent inactivated vaccine.

\section{Competing interests}

JVC declares that he has no competing interests. WHC has been a paid consultant of AlphaVax, LigoCyte Pharmaceuticals, Integrated BioTherapeutics, and Toyama Chemical Co.

\section{Acknowledgements}

The present work was supported in part by grants from the National Institutes of Health, Department of Health and Human Services, USA (K12-RR023250 to $\mathrm{WHC}$

\section{Author details}

'Infectious Disease, University of Maryland Medical Center, 725 W Lombard Street, N550, Baltimore, MD 21201, USA. ${ }^{2}$ Center for Vaccine Development, 685 W Baltimore Street, HSF1, Room 480, Baltimore, MD 21201, USA.

Published: 16 April 2010

\section{References}

1. Smith NM, Bresee JS, Shay DK, Uyeki TM, Cox NJ, Strikas RA: Prevention and control of influenza: recommendations of the Advisory Committee on Immunization Practices (ACIP). MMWR Recomm Rep 2006, 55:1-42.

2. Johnson NP, Mueller J: Updating the accounts: global mortality of the 1918-1920 'Spanish' influenza pandemic. Bull Hist Med 2002, 76:105-115.

3. Patterson KD, Pyle GF: The geography and mortality of the 1918 influenza pandemic. Bull Hist Med 1991, 65:4-21.

4. Hilleman MR: Vaccines in historic evolution and perspective: a narrative of vaccine discoveries. Vaccine 2000, 18:1436-1447.

5. WHO GAR, Global Alert and Response: Summary of Available Potency Testing Reagents for Pandemic (H1N1) 2009 Virus Vaccines - Update. Geneva: WHO; 20 November 2009 [http://www.who.int/csr/resources/publications/swineflu/ cp111b_2009_2011_summary_srid_reagents_H1N1_update.pdf].

6. Ambrose CS, Luke C, Coelingh K: Current status of live attenuated influenza vaccine in the United States for seasonal and pandemic influenza. Influenza Other Respi Viruses 2008, 2:193-202.

7. Belshe RB, Edwards KM, Vesikari T, Black SV, Walker RE, Hultquist M, Kemble G, Connor EM: Live attenuated versus inactivated influenza vaccine in infants and young children. N Engl J Med 2007, 356:685-696.

8. Piedra PA, Gaglani MJ, Kozinetz CA, Herschler G, Riggs M, Griffith M, Fewlass C, Watts M, Hessel C, Cordova J, Glezen WP: Herd immunity in adults against influenza-related illnesses with use of the trivalent-live attenuated influenza vaccine (CAIV-T) in children. Vaccine 2005, 23:1540-1548.

9. Maassab HF: Plaque formation of influenza virus at $25^{\circ} \mathrm{C}$. Nature 1968 , 219:645-646.

10. Neumann G, Noda T, Kawaoka Y: Emergence and pandemic potential of swine-origin H1N1 influenza virus. Nature 2009, 459:931-939.

11. Alexandrova Gl, Maassab HF, Kendal AP, Medvedeva TE, Egorov AY, Klimov Al, Cox NJ: Laboratory properties of cold-adapted influenza $B$ live vaccine strains developed in the US and USSR, and their B/Ann Arbor/1/86 coldadapted reassortant vaccine candidates. Vaccine 1990, 8:61-64.

12. Kendal AP, Maassab HF, Alexandrova Gl, Ghendon YZ: Development of coldadapted recombinant live, attenuated influenza $A$ vaccines in the U.S.A. and U.S.S.R. Antiviral Res 1982, 1:339-365.

13. Rimmelzwaan GF, McElhaney JE: Correlates of protection: novel generations of influenza vaccines. Vaccine 2008, 26:D41-D44.

14. deJong JC, Palache AM, Beyer WE, Rimmelzwaan GF, Boon AC, Osterhaus AD: Haemagglutination-inhibiting antibody to influenza virus. Dev Biol (Basel) 2003, 115:63-73.

15. Beutner KR, Chow T, Rubi E, Strussenberg J, Clement J, Ogra PL: Evaluation of a neuraminidase-specific influenza $A$ virus vaccine in children: antibody responses and effects on two successive outbreaks of natural infection. J Infect Dis 1979, 140:844-850.

16. Chen Z, Kadowaki S, Hagiwara Y, Yoshikawa T, Matsuo K, Kurata T, Tamura S: Cross-protection against a lethal influenza virus infection by DNA vaccine to neuraminidase. Vaccine 2000, 18:3214-3222.

17. Johansson BE, Matthews JT, Kilbourne ED: Supplementation of conventional influenza A vaccine with purified viral neuraminidase results in a balanced and broadened immune response. Vaccine 1998, 16:1009-1015.

18. Schulman JL, Khakpour M, Kilbourne ED: Protective effects of specific immunity to viral neuraminidase on influenza virus infection of mice. J Virol 1968, 2:778-786.

19. Johansson BE, Bucher DJ, Kilbourne ED: Purified influenza virus hemagglutinin and neuraminidase are equivalent in stimulation of antibody response but induce contrasting types of immunity to infection. J Virol 1989, 63:1239-1246.

20. Taylor HP, Dimmock NJ: Mechanism of neutralization of influenza virus by secretory $\lg \mathrm{A}$ is different from that of monomeric $\lg \mathrm{A}$ or $\lg \mathrm{G}$. J Exp Med 1985, 161:198-209.

21. Tamura S, Kurata T: Defense mechanisms against influenza virus infection in the respiratory tract mucosa. Jpn J Infect Dis 2004, 57:236-247.

22. Miller MA, Viboud C, Balinska M, Simonsen L: The signature features of influenza pandemics - implications for policy. N Engl J Med 2009, 360:2595-2598.

23. Baylor NW, Houn F: Considerations for licensure of influenza vaccines with pandemic and prepandemic indications. Curr Top Microbiol Immunol 2009, 333:453-470.

24. The Division of Vaccine and Related Product Applications, Center for Biologics Evaluation and Research, FDA: Guidance for Industry: Clinical Data Needed to Support the Licensure of Pandemic Influenza Vaccines. Rockville, MD: US Food 
and Drug Administration; 2007 [http://www.fda.gov/downloads/ BiologicsBloodVaccines/GuidanceComplianceRegulatorylnformation/ Guidances/Naccines/ucm091990.pdf].

25. Stephenson I, Gust I, Kieny MP, Pervikov Y: Development and evaluation of influenza pandemic vaccines. Lancet Infect Dis 2006, 6:71-72.

26. Fedson DS: Preparing for pandemic vaccination: an international policy agenda for vaccine development. J Public Health Policy 2005, 26:4-29.

27. Webby RJ, Perez DR, Coleman JS, Guan Y, Knight JH, Govorkova EA, ClainMoss LR, Peiris JS, Rehg JE, Tuomanen El, Webster RG: Responsiveness to a pandemic alert: use of reverse genetics for rapid development of influenza vaccines. Lancet 2004, 363:1099-1103.

28. Schonberger LB, Bregman DJ, Sullivan-Bolyai JZ, Keenlyside RA, Ziegler DW, Retailliau HF, Eddins DL, Bryan JA: Guillain-Barré syndrome following vaccination in the National Influenza Immunization Program, United States, 1976-1977. Am J Epidemiol 1979, 110:105-123.

29. Nachamkin I, Shadomy SV, Moran AP, Cox N, Fitzgerald C, Ung H, Corcoran AT, Iskander JK, Schonberger LB, Chen RT: Anti-ganglioside antibody induction by swine (A/NJ/1976/H1N1) and other influenza vaccines: insights into vaccine-associated Guillain-Barré syndrome. J Infect Dis 2008, 198:226-233.

30. Geier MR, Geier DA, Zahalsky AC: Influenza vaccination and Guillain Barré syndrome small star, filled. Clin Immunol 2003, 107:116-121.

31. Hughes RA, Cornblath DR: Guillain-Barré syndrome. Lancet 2005, 366:1653-1666.

32. Evans D, Cauchemez S, Hayden FG: 'Prepandemic' immunization for novel influenza viruses, 'swine flu' vaccine, Guillain-Barré syndrome, and the detection of rare severe adverse events. J Infect Dis 2009, 200:321-328.

33. Eisen DP, McBryde ES: Avoiding Guillan-Barré syndrome following swine origin pandemic H1N1 2009 influenza vaccination. J Infect Dis 2009, 200:1627-1628.

34. Audsley JM, Tannock GA: Cell-based influenza vaccines: progress to date. Drugs 2008, 68:1483-1491.

35. Gaush CR, Smith TF: Replication and plaque assay of influenza virus in an established line of canine kidney cells. App/ Microbiol 1968, 16:588-594.

36. Meguro H, Bryant JD, Torrence AE, Wright PF: Canine kidney cell line for isolation of respiratory viruses. J Clin Microbiol 1979, 9:175-179.

37. Szymczakiewicz-Multanowska A, Groth N, Bugarini R, Lattanzi M, Casula D, Hilbert A, Tsai T, Podda A: Safety and immunogenicity of a novel influenza subunit vaccine produced in mammalian cell culture. J Infect Dis 2009, 200:841-848.

38. Halperin SA, Nestruck AC, Eastwood BJ: Safety and immunogenicity of a new influenza vaccine grown in mammalian cell culture. Vaccine 1998, 16:1331-1335

39. Halperin SA, Smith B, Mabrouk T, Germain M, Trepanier P, Hassell T, Treanor J, Gauthier R, Mills EL: Safety and immunogenicity of a trivalent, inactivated, mammalian cell culture-derived influenza vaccine in healthy adults, seniors, and children. Vaccine 2002, 20:1240-1247.

40. Palache AM, Brands R, van Scharrenburg GJ: Immunogenicity and reactogenicity of influenza subunit vaccines produced in MDCK cells or fertilized chicken eggs. J Infect Dis 1997, 176(Suppl 1):S20-S23.

41. Merten OW: Development of serum-free media for cell growth and production of viruses/viral vaccines - safety issues of animal products used in serum-free media. Dev Biol (Basel) 2002, 111:233-257.

42. Treanor JJ, Campbell JD, Zangwill KM, Rowe T, Wolff M: Safety and immunogenicity of an inactivated subvirion influenza A (H5N1) vaccine. NEngl J Med 2006, 354:1343-1351.

43. Brady RC, Treanor JJ, Atmar RL, Keitel WA, Edelman R, Chen WH, Winokur P, Belshe R, Graham IL, Noah DL, Guo K, Hill H: Safety and immunogenicity of a subvirion inactivated influenza A/H5N1 vaccine with or without aluminum hydroxide among healthy elderly adults. Vaccine 2009 , 27:5091-5095.

44. Keitel WA, Campbell JD, Treanor JJ, Walter EB, Patel SM, He F, Noah DL, Hill H: Safety and immunogenicity of an inactivated influenza $\mathrm{A} / \mathrm{H} 5 \mathrm{~N} 1$ vaccine given with or without aluminum hydroxide to healthy adults: results of a phase I-II randomized clinical trial. J Infect Dis 2008, 198:1309-1316.

45. Global Advisory Committee on Vaccine Safety, World Health Organization: Statement from WHO Global Advisory Committee on Vaccine Safety about the Safety Profile of Pandemic Influenza A (H1N1) 2009 Vaccines. Geneva: WHO; 18 December 2009 [http://www.who.int/csr/resources/publications/swineflu/ cp164_2009_1612_gacvs_h1n1_vaccine_safety.pdf].

46. Banzhoff A, Gasparini R, Laghi-Pasini F, Staniscia T, Durando P, Montomoli E, Capecchi PL, di GP, Sticchi L, Gentile C, Hilbert A, Brauer V, Tilman S, Podda A:
MF59-adjuvanted H5N1 vaccine induces immunologic memory and heterotypic antibody responses in non-elderly and elderly adults. PLoS One 2009, 4:e4384.

47. Bernstein DI, Edwards KM, Dekker CL, Belshe R, Talbot HK, Graham IL, Noah DL, He F, Hill H: Effects of adjuvants on the safety and immunogenicity of an avian influenza H5N1 vaccine in adults. J Infect Dis 2008, 197:667-675.

48. Levie K, Leroux-Roels I, Hoppenbrouwers K, Kervyn AD, Vandermeulen C, Forgus S, Leroux-Roels G, Pichon S, Kusters I: An adjuvanted, low-dose, pandemic influenza A (H5N1) vaccine candidate is safe, immunogenic, and induces cross-reactive immune responses in healthy adults. J Infect Dis 2008, 198:642-649

49. Beyer WE, Palache AM, Osterhaus AD: Comparison of serology and reactogenicity between influenza subunit vaccines and whole virus or split vaccines: a review and meta-analysis of the literature. Clin Drug Investig 1998, 15:1-12

50. Geeraedts F, Bungener L, Pool J, Ter VW, Wilschut J, Huckriede A: Whole inactivated virus influenza vaccine is superior to subunit vaccine in inducing immune responses and secretion of proinflammatory cytokines by DCs. Influenza Other Respi Viruses 2008, 2:41-51.

51. Ortbals DW, Liebhaber $\mathrm{H}$ : Comparison of immunogenicity of a whole virion and a subunit influenza vaccine in adults. J Clin Microbiol 1978, 8:431-434.

52. Stephenson I, Nicholson KG, Gluck R, Mischler R, Newman RW, Palache AM, Verlander NQ, Warburton F, Wood JM, Zambon MC: Safety and antigenicity of whole virus and subunit influenza A/Hong Kong/1073/99 (H9N2) vaccine in healthy adults: phase I randomised trial. Lancet 2003, 362:1959-1966.

53. Treanor JJ, Betts RF, Smith GE, Anderson EL, Hackett CS, Wilkinson BE, Belshe $R B$, Powers DC: Evaluation of a recombinant hemagglutinin expressed in insect cells as an influenza vaccine in young and elderly adults. J Infect Dis 1996, 173:1467-1470.

54. Treanor J, Schiff GM, Couch RB, Cate TR, Brady RC, Hay CM, Wolff M, She D, Cox MM: Dose-related safety and immunogenicity of a trivalent baculovirus-expressed influenza-virus hemagglutinin vaccine in elderly adults. J Infect Dis 2006, 193:1223-1228.

55. Treanor JJ, Schiff GM, Hayden FG, Brady RC, Hay CM, Meyer AL, Holden-Wiltse J, Liang H, Gilbert A, Cox M: Safety and immunogenicity of a baculovirusexpressed hemagglutinin influenza vaccine: a randomized controlled trial. JAMA 2007, 297:1577-1582.

56. Haynes JR: Influenza virus-like particle vaccines. Expert Rev Vaccines 2009 8:435-445

57. Galarza JM, Latham T, Cupo A: Virus-like particle (VLP) vaccine conferred complete protection against a lethal influenza virus challenge. Viral Immunol 2005, 18:244-251.

58. Moss RB: Prospects for control of emerging infectious diseases with plasmid DNA vaccines. J Immune Based Ther Vaccines 2009, 7:3.

59. Lalor PA, Webby RJ, Morrow J, Rusalov D, Kaslow DC, Rolland A, Smith LR Plasmid DNA-based vaccines protect mice and ferrets against lethal challenge with A/Vietnam/1203/04 (H5N1) influenza virus. J Infect Dis 2008, 197:1643-1652.

60. Schotsaert M, De FM, Fiers W, Saelens X: Universal M2 ectodomain-based influenza A vaccines: preclinical and clinical developments. Expert Rev Vaccines 2009, 8:499-508.

61. Neirynck S, Deroo T, Saelens X, Vanlandschoot P, Jou WM, Fiers W: A universal influenza $A$ vaccine based on the extracellular domain of the M2 protein. Nat Med 1999, 5:1157-1163.

62. Novel influenza $A(H 1 N 1) v$ investigation team: Description of the early stage of pandemic (H1N1) 2009 in Germany, 27 April-16 June 2009. Euro Surveill 2009, 14:pii $=19295$.

63. Jain S, Kamimoto L, Bramley AM, Schmitz AM, Benoit SR, Louie J, Sugerman DE, Druckenmiller JK, Ritger KA, Chugh R, Jasuja S, Deutscher M, Chen S, Walker JD, Duchin JS, Lett S, Soliva S, Wells EV, Swerdlow D, Uyeki TM, Fiore AE, Olsen SJ, Fry AM, Bridges CB, Finelli L: Hospitalized patients with 2009 H1N1 influenza in the United States, April-June 2009. N Engl J Med 2009, 361:1935-1944.

64. Kelly H, Grant K: Interim analysis of pandemic influenza (H1N1) 2009 in Australia: surveillance trends, age of infection and effectiveness of seasonal vaccination. Euro Surveill 2009, 14:pii=19288.

65. Vaillant L, La RG, Tarantola A, Barboza P: Epidemiology of fatal cases associated with pandemic H1N1 influenza 2009. Euro Surveill 2009, 14:pii=19309.

66. Manzoli L, Salanti G, De VC, Boccia A, loannidis JP, Villari P: Immunogenicity 
and adverse events of avian influenza A H5N1 vaccine in healthy adults: multiple-treatments meta-analysis. Lancet Infect Dis 2009, 9:482-492.

67. Beigel JH, Voell J, Huang CY, Burbelo PD, Lane HC: Safety and immunogenicity of multiple and higher doses of an inactivated influenza A/H5N1 vaccine. J Infect Dis 2009, 200:501-509.

68. Update on influenza A (H1N1) 2009 monovalent vaccines. MMWR Morb Mortal Wkly Rep 2009, 58:1100-1101.

69. Greenberg ME, Lai MH, Hartel GF, Wichems CH, Gittleson C, Bennet J, Dawson
G, Hu W, Leggio C, Washington D, Basser RL: Response to a monovalent 2009 influenza A (H1N1) vaccine. N Eng/ J Med 2009, 361:2405-2413.

doi:10.1186/cc8891

Cite this article as: Chua JV, Chen WH: Bench-to-bedside review: Vaccine protection strategies during pandemic flu outbreaks. Critical Care 2010, 14:218 